\title{
Association of Sleep Dysfunction and Emotional Status With Gastroesophageal Reflux Disease in Korea
}

\author{
Ji Yeon Kim, ${ }^{1,2}$ Nayoung Kim, ${ }^{1,2 *}$ Pyoung Ju Seo, ${ }^{1}$ Jung Won Lee, ${ }^{2}$ Min Soo Kim, ${ }^{1}$ Sung Eun Kim, ${ }^{1}$ So Young Jo, \\ Dong Ho Lee ${ }^{1,2}$ and Hyun Chae Jung ${ }^{2}$ \\ ${ }^{1}$ Department of Internal Medicine, Seoul National University Bundang Hospital, Seongnam, Gyeonggi-do, Korea; and ${ }^{2}$ Department of Internal \\ Medicine and Liver Research Institute, Seoul National University College of Medicine, Seoul, Korea
}

\begin{abstract}
Background/Aims
Sleep disturbances and emotional dysfunction are commonly associated with gastroeophageal reflux disease (GERD). The aims of this study were to evaluate GERD symptoms and disturbance in erosive reflux disease (ERD) and nonerosive reflux disease (NERD) patients, and to compare sleep dysfunction, depressive mood, anxiety and quality of life (QOL) among the control, ERD and NERD patients in Korea.
\end{abstract}

\section{Methods}

The Korean subjects were enrolled between 2010 and 2012, classified into 3 groups; the control group with no symptom and normal endoscopic findings, the ERD group with erosive esophagitis and the NERD group with more than one episode of heartburn or acid regurgitation per week, positive response to proton pump inhibitor, and normal endoscopic findings. Questionnaire included GERD symptoms, GERD impact scale (GIS) and daytime pathological sleepiness (Epworth sleepiness scale), sleep dysfunction (Pittsburgh sleep quality index, PSQI), depression and anxiety (Hospital anxiety and depression scale, HADS) and QOL (WHO quality of life scale abbreviated version, WHOQOL-BREF).

Results

A total of 217 subjects were enrolled as follows; control $(n=70)$, ERD $(n=70)$ and NERD $(n=77)$. Impact of symptom of GIS score was higher in the NERD $(9.2 \pm 0.4)$ than in the ERD $(6.5 \pm 0.3)$ group $(P<0.001)$. Sleep dysfunctions were more frequent in GERD than the control group (PSQI score $[P=0.021]$ ). Anxiety subscale of HAD score was higher in NERD $(7.0 \pm 0.5, P=0.002)$ and ERD $(6.2 \pm 0.7, P=0.004)$ groups than control $(4.3 \pm 0.7)$ group. WHOQOL-BREF scores in $\operatorname{NERD}(54.9 \pm 2.3)$ and ERD $(57.8 \pm 2.4)$ groups were significantly lower than those in the control group (63.8 \pm 2.4$)(P$ $=0.002 ; P=0.014$, respectively).

Received: March 27, 2013 Revised: June 12, 2013 Accepted: June 15, 2013

(c) This is an Open Access article distributed under the terms of the Creative Commons Attribution Non-Commercial License (http://creativecommons. org/licenses/by-nc/3.0) which permits unrestricted non-commercial use, distribution, and reproduction in any medium, provided the original work is properly cited. *Correspondence: Nayoung Kim, MD

Department of Internal Medicine, Seoul National University Bundang Hospital, 82, Gumi-ro 173 beon-gil, Bundang-gu, Gyeonggi-do 463-707, Korea

Tel: +82-31-787-7008, Fax: +82-31-787-4051, E-mail: nayoungkim49@empas.com

Financial support: This work was supported by the National Research Foundation of Korea (NRF) grant for the Global Core Research Center (GCRC) funded by the Korea government (MSIP) (No. 2011-0030001).

Conflicts of interest: None.

Author contributions: All authors have contributed to and agreed on the content of the manuscript. Ji Yeon Kim analyzed and interpreted the data and wrote the present study and Nayoung Kim designed, organized and mediated the present study and supervised the manuscript. Pyoung Ju Seo made a questionnaire used in the present study and Min Soo Kim and Sung Eun Kim input and organized the data for statistical analysis. So Young Jo, Jung Won Lee and Dong Ho Lee performed the statistical analysis and helped analysis of data. Hyng Chae Jung supervised overall study. 


\section{Conclusions}

The patients with NERD than ERD suffered more from the symptoms and disturbance in Korea. Sleep dysfunction and anxiety mood were higher and QOL was decreased in GERD, especially in NERD, suggesting that those factors might affect the severity of NERD.

(J Neurogastroenterol Motil 2013;19:344-354)

\section{Key Words}

Emotions; Gastroesophageal reflux; Quality of life; Sleep

\section{Introduction}

Gastroesophageal reflux disease (GERD) is defined as a condition that develops when the reflux of stomach contents causes troublesome symptoms and/or complications. ${ }^{1}$ GERD is one of the most common and chronic gastrointestinal (GI) disorder. ${ }^{2}$ Recently, the prevalence of GERD showed increasing tendency in Asia. ${ }^{3,4}$ Similarly, a multi-center cross-sectional review demonstrated that the prevalence of GERD is increasing up to $5 \%$ in the 2000 s in Korea, ${ }^{5}$ which implies that GERD has become important health care burden in Korea.

The symptomatic presentations of GERD are associated with various psychosocial and physical factors, such as chronic stress or emotional dysfunction, ${ }^{6}$ abnormal reflux of gastric acid ${ }^{7}$ and obesity. ${ }^{8}$ It has been recognized that sleep disturbance and emotional dysfunction are commonly associated with GERD. Sleep disorders may cause GI disturbances, while GI symptoms may provoke or worsen sleep derangements. ${ }^{9}$ In addition, prolonged acid contact time during sleep disturbances may provoke GERD. ${ }^{10}$ However, most of the studies were performed from Western countries, and, to our best knowledge, there has been no study about the relationship between sleep and GERD in Korea so far. Emotional dysfunction, including anxiety and depression, is also associated with GERD. A previous report suggested that anxiety and depression were related with reflux symptoms, while no consistent association regarding reflux was found. ${ }^{6}$ Quality of life (QOL) is influenced by various factors, including sleep and emotional status. As GERD affects these factors, QOL could be affected by GERD. ${ }^{11}$

GERD is classified into erosive reflux disease (ERD) and nonerosive reflux disease (NERD). Initially, NERD had been recognized as a mild form of ERD and it was generally accepted that NERD progresses to Barrett's esophagus through ERD. ${ }^{12}$ However, recently, NERD is considered as a distinct categorical disease from $\mathrm{ERD}^{13}$ and progression to $\mathrm{ERD}$ is relatively uncommon. ${ }^{14,15}$ In addition, various differences in epidemiology, pathophysiology, symptoms, and therapeutic response have been observed between NERD and ERD. ${ }^{16-19}$

From these backgrounds, the aims of the present study were to evaluate the symptoms and disturbances between ERD and NERD patients and to compare sleep dysfunction, depressive mood, anxiety and overall QOL of the controls, ERD and NERD patients in Korea.

\section{Materials and Methods}

\section{Study Subjects}

The subjects were enrolled prospectively at Seoul National University Bundang Hospital (SNUBH), between March 2010 and November 2012. All the subjects should receive upper GI endoscopy and should complete questionnaires about GERD symptoms, sleep characteristics, emotional status and QOL under the supervision of a well-trained interviewer. For the control, the subjects receiving health check-up examinations were enrolled. The inclusion criteria for the control group included normal upper GI endoscopic findings, and no symptom related to GERD confirmed by questionnaires. For control, the subjects who did not meet the exclusion criteria were enrolled when they were willing to participate in this study and sincerely accomplished the questionnaire. For the ERD and NERD groups, GERD patients having visited the outpatient clinic of one gastroenterologist (N Kim) were enrolled. The inclusion criteria for ERD and NERD groups were endoscopic findings and symptoms related to GERD confirmed by questionnaires. Following subjects were excluded; (1) subjects who had received upper GI surgery; (2) subjects who had any organic lesions on upper GI endoscopy including peptic ulcer disease and malignancy, except erosive esophagitis; (3) subjects who had taken proton pump in- 
hibitor (PPI) or $\mathrm{H}_{2}$ blocker within 1 month; and (4) for NERD group, subjects who had symptoms lesser than one episode of heartburn or acid regurgitation per week, or did not respond to PPI. All subjects were of Korean origin. The study protocol was approved by the Ethical Committee at SNUBH and all subjects were provided with informed consent.

\section{Classification of Erosive Reflux Disease, Nonerosive Relux Disease and Control Group}

The subjects were classified into 3 groups; ERD, NERD and control group. ERD was defined by the presence of mucosal breaks at gastroesophageal junction in endoscopic finding, according to the Los Angeles (LA) classification of esophagitis. ${ }^{20}$ The minimal change of reflux esophagitis was not designated as ERD. NERD was defined as more than one episode of heartburn or acid regurgitation per week with normal endoscopic finding, and positive response of PPI trial, meaning that more than $50 \%$ of symptom frequency were improved after 2-week PPI intake. Subjects with no symptom and normal endoscopic finding from health check-up were assigned as the control group. Biopsy was not done who had normal endoscopic finding.

\section{Questionnaires}

The clinical information of the subjects, including age, gender, medications, smoking, alcohol intake and monthly income were investigated. The 2 questionnaires were used to evaluate GERD symptoms. Seven GERD symptoms which consisted of esophageal and extra-esophageal symptoms were checked. Esophageal symptoms were heartburn and acid regurgitation, and extra-esophageal symptoms were chest pain, cough, globus symptoms, hoarseness, and epigastric soreness. GERD impact scale (GIS) was also used to assess GERD symptoms and impact of these symptoms on everyday life. The GIS is a validated questionnaire that was developed from systematic literature review and has been demonstrated to have good psychometric properties in diagnosis and is considered as a useful communication tool in managing GERD. ${ }^{21}$ GIS consists of 5 questions about symptoms and 4 questions about impact of symptoms on sleep, eating or drinking, job or daily activities and taking medication without prescription. ${ }^{22}$ Subjects answered each question by 4 scales; 3 point for 'daily', 2 for 'often', 1 for 'sometimes' and zero for 'never.' The use of text of the GIS was generously permitted from AstraZeneca LP (C)2001).

Pittsburgh sleep quality index (PSQI) ${ }^{23}$ and Epworth sleepi- ness scale (ESS) ${ }^{24}$ were used to determine sleep dysfunction. The PSQI is a standardized rating scale, in which 19 individual items generate 7 component scores: subjective sleep quality, sleep latency, sleep duration, habitual sleep efficiency, sleep disturbances, use of sleeping medication, and daytime dysfunction. Each dimension is rated on a 4-point scale and the sum of scores for these 7 components yields one global score. Higher score means that the subject is more disturbed during sleep and more than the score of 5 indicates poor sleep. The ESS measures subject's general level of daytime sleepiness. ${ }^{24}$ It consists of 8 self-rated items, each scored from 0-3 that measures a subject's habitual 'likelihood of dozing or falling asleep' in common situations of daily living. The ESS score represents the sum of individual items. Higher ESS scores mean that the subject is sleepier during daytime and more than the score of 10 indicates significant sleepiness.

Hospital anxiety and depression scale (HADS) was used to identify possible anxiety and depression among nonpsychiatric subjects. It is divided into anxiety and depression subscales, both containing 7 items. Each item is answered on a 4 point (0-3) response category. Higher HADS score denotes that the subject is more depressive or anxious, and more than a score of 7 of each subscale means potential anxiety disorder or depression. ${ }^{25}$

World Health Organization quality of life scale abbreviated version (WHOQOL-BREF) ${ }^{26,27}$ was used to assess the QOL of subjects. It consists of questions of overall QOL and general health, and 4 domains as the following: physical health, medical treatment, psychological health and environmental domains, including access to health services. Its results are expressed as an overall score (range 0-100) and domain score (range 0-100) with higher score indicating better QOL.

These 4 questionnaires (PSQI, ESS, HADS and WHOQOLBREF) were validated in Korean. ${ }^{28-31}$

\section{Statistical Methods}

SPSS for Windows (version 18.0; SPSS, Chicago, IL, USA) was used for all statistical analyses. Continuous variables were analyzed by using Student's $t$ test, one-way ANOVA, Kruskal-Wallis test or Mann-Whitney test. Scheffe test was done as a post-hoc test. The $\chi^{2}$-test, Fisher's exact test or Cochran's $\mathrm{Q}$ test were used for analysis of categorical variables. ANCOVA was used for the adjustment in gender, age, body mass index (BMI), cigarette smoking, alcohol intake and income. All results were considered statistically significant when $P$-values were $<0.05$. 


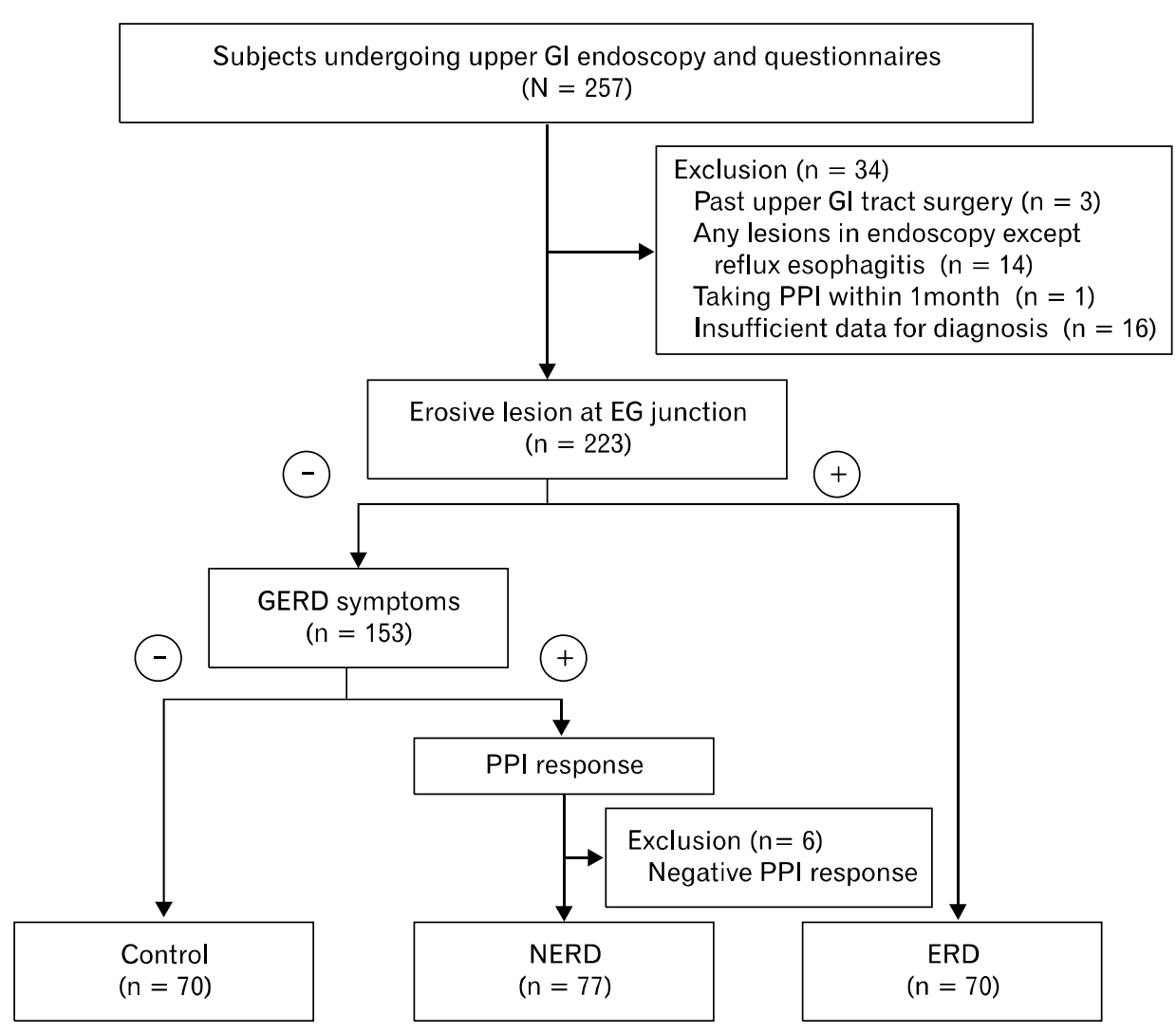

Figure. Flow chart of study patients. GI, gastrointestinal; EG, esophageogastric; PPI, proton pump inhibitor; GERD, gastroesophageal reflux disease; NERD, nonerosive reflux disease; ERD, erosive reflux disease.

Table 1. Characteristics of the Participating Subjects

\begin{tabular}{|c|c|c|c|c|c|}
\hline & Control $(\mathrm{n}=70)$ & $\operatorname{ERD}(\mathrm{n}=70)$ & $\operatorname{NERD}(\mathrm{n}=77)$ & $P$-value & ERD vs. NERD \\
\hline Age $($ mean $\pm \mathrm{SD}, \mathrm{yr})$ & $45.3 \pm 11.6$ & $53.2 \pm 13.7$ & $53.4 \pm 13.8$ & $<0.001^{\mathrm{a}, \mathrm{b}}$ & 0.966 \\
\hline Gender (n [\%]) & & & & $<0.001^{\mathrm{a}}$ & $<0.001$ \\
\hline Male & $35(50.0)$ & $57(81.4)$ & $40(51.9)$ & & \\
\hline Female & $35(50.0)$ & $13(18.6)$ & $37(48.1)$ & & \\
\hline Cigarette smoking (n [\%]) & $28(40.0)$ & $36(52.2)$ & $26(34.7)$ & 0.049 & 0.043 \\
\hline Alcohol intake (n [\%]) & $36(51.4)$ & $49(71.1)$ & $35(46.1)$ & $<0.001^{\mathrm{b}}$ & 0.003 \\
\hline $\mathrm{BMI}\left(\right.$ mean $\left.\pm \mathrm{SD}, \mathrm{kg} / \mathrm{m}^{2}\right)$ & $22.8 \pm 3.1$ & $24.6 \pm 3.1$ & $23.5 \pm 3.2$ & $0.001^{\mathrm{a}}$ & 0.019 \\
\hline Male & $24.2 \pm 2.5$ & $24.7 \pm 3.2$ & $23.9 \pm 2.8$ & 0.398 & 0.432 \\
\hline Female & $21.3 \pm 3.0$ & $24.3 \pm 2.8$ & $22.5 \pm 3.2$ & $0.014^{\mathrm{a}}$ & 0.204 \\
\hline Past history of GERD (n [\%]) & $16(23.2)$ & $44(63.8)$ & $56(72.7)$ & $<0.001^{\mathrm{a}, \mathrm{b}}$ & 0.286 \\
\hline \multicolumn{6}{|l|}{ Comorbidity (n $[\%]$ ) } \\
\hline Hypertension & $6(8.8)$ & $21(34.4)$ & $14(21.9)$ & $0.002^{\mathrm{a}, \mathrm{b}}$ & 0.163 \\
\hline Diabetes mellitus & $3(4.5)$ & $5(5.0)$ & $5(7.8)$ & $0.737^{\mathrm{c}}$ & $0.719^{\mathrm{d}}$ \\
\hline Psychiatry & $0(0.0)$ & $4(6.6)$ & $7(10.9)$ & $0.012^{\mathrm{b}, \mathrm{c}}$ & 0.531 \\
\hline Sedative, anti-depressant agent & $0(0.0)$ & $5(7.9)$ & $7(10.9)$ & $0.018^{\mathrm{a}, \mathrm{b}, \mathrm{c}}$ & 0.765 \\
\hline Income (n $[\%])$ & & & & $0.031^{\mathrm{b}}$ & 0.044 \\
\hline$\leq 5,000,000 \#$ & $23(44.2)$ & $26(46.4)$ & $44(65.7)$ & & \\
\hline$>5,000,000 \#$ & $29(55.8)$ & $30(53.6)$ & $23(34.3)$ & & \\
\hline
\end{tabular}

ERD, erosive reflux disease; NERD, nonerosive reflux disease; BMI, body mass index; GERD, gastroesophageal reflux disease; \#, the currency of South Korea. ${ }^{\mathrm{a}} P<0.05$ in comparing control and ERD group; ${ }^{\mathrm{b}} P<0.05$ in comparing control and NERD group; ${ }^{\mathrm{c}} P$-value was analyzed by Cochran's $\mathrm{Q}$ test; ${ }^{\mathrm{d}} P$-value was analyzed by Fisher's exact test. 


\section{Results}

\section{Classification of Subjects}

Two hundred and fifty-seven subjects underwent upper GI endoscopy and answered the questionnaires. Three patients who received upper GI tract surgery, 14 patients who had other lesions except reflux esophagitis in upper GI endoscopy, 1 patient who had taken PPI within 1 month, 16 patients who had not completed the questionnaires fully, and 6 patients with negative response of PPI trial were excluded. Finally, a total of 217 subjects were enrolled in this study. They were classified into 3 groups, according to endoscopic findings and GERD symptoms; 70 patients into the ERD group, 77 patients into the NERD group and 70 subjects into the control group (Figure). Of 70 patients in the ERD group, 47 patients had LA-A, and 23 patients had LA-B. Between them, baseline characteristics were not different. Hence we analyzed all of those as ERD group.

\section{Characteristics of Participating Subjects}

Table 1 shows the baseline characteristics of the subjects among the 3 groups, and then the comparison of ERD with NERD. There were more male patients in the ERD group $(81.4 \%)$ than the control $(50.0 \%)$ and NERD (51.9\%) groups $(P<0.001)$. Female proportion was higher in the NERD group $(48.1 \%)$ than in the ERD group $(18.6 \%)(P<0.001)$. Smoker and alcohol consumer were more prevalent in the ERD group (52.2\% and $71.1 \%$ ) than in the NERD group $(34.7 \%$ and 46.1\%) $(P=0.043$ and $P=0.003)$. BMI was higher in the ERD group $\left(24.6 \pm 3.1 \mathrm{~kg} / \mathrm{m}^{2}\right)$ than the control $(22.8 \pm 3.1$ $\left.\mathrm{kg} / \mathrm{m}^{2}\right)$ and NERD $\left(23.5 \pm 3.2 \mathrm{~kg} / \mathrm{m}^{2}\right)$ groups $(P=0.001)$. Monthly income was significantly lower in the NERD group than the control and ERD group $(P=0.031)$.

Table 2. Reflux Symptoms and Gastroesophageal Reflux Disease Impact Scale in Erosive Reflux Disease and Nonerosive Reflux Disease

\begin{tabular}{|c|c|c|c|}
\hline & $\operatorname{ERD}(\mathrm{n}=70)$ & $\operatorname{NERD}(\mathrm{n}=77)$ & $P$-value \\
\hline Any one of following 7 symptoms (n [\%]) & $60(85.7)$ & $77(100.0)$ & 0.025 \\
\hline Heartburn & $51(73.9)$ & $68(88.3)$ & 0.033 \\
\hline Acid regurgitation & $50(73.5)$ & $67(87.0)$ & 0.057 \\
\hline Chest pain & $39(57.4)$ & $67(87.0)$ & $<0.001$ \\
\hline Hoarseness & $34(49.3)$ & $52(67.5)$ & 0.029 \\
\hline Globus sensation & $39(56.5)$ & $59(76.6)$ & 0.013 \\
\hline Cough & $41(59.4)$ & $45(58.4)$ & 0.999 \\
\hline Epigastric soreness & $42(60.9)$ & $62(81.6)$ & 0.009 \\
\hline Esophageal symptoms (n [\%]) & $56(81.2)$ & $77(100.0)$ & 0.002 \\
\hline \multirow[t]{2}{*}{ Extra-esophageal symptoms (n [\%]) } & $54(78.3)$ & $74(96.1)$ & 0.002 \\
\hline & ERD with symptoms $(\mathrm{n}=60)$ & $\operatorname{NERD}(\mathrm{n}=77)$ & $P$-value \\
\hline Heartburn (n [\%]) & $51(85.0)$ & $68(88.3)$ & 0.616 \\
\hline Acid regurgitation (n [\%]) & $50(84.7)$ & $67(87.0)$ & 0.804 \\
\hline Chest pain (n [\%]) & $39(66.1)$ & $67(87.0)$ & 0.006 \\
\hline Hoarseness (n [\%]) & $34(56.7)$ & $52(67.5)$ & 0.215 \\
\hline Globus sensation (n [\%]) & $39(65.0)$ & $59(76.6)$ & 0.181 \\
\hline Cough (n $[\%])$ & $41(68.3)$ & $45(58.4)$ & 0.286 \\
\hline Epigastric soreness (n [\%]) & $42(70.0)$ & $62(81.6)$ & 0.154 \\
\hline Esophageal symptoms (n [\%]) & $56(93.3)$ & $77(100.0)$ & 0.405 \\
\hline \multirow[t]{2}{*}{ Extra-esophageal symptoms (n [\%]) } & $54(90.0)$ & $74(96.1)$ & 0.179 \\
\hline & ERD with symptoms $(\mathrm{n}=60)$ & $\operatorname{NERD}(\mathrm{n}=77)$ & $P$-value \\
\hline \multicolumn{4}{|l|}{ GIS } \\
\hline GERD symptoms (mean $\pm \mathrm{SE})$ & $9.8 \pm 0.4$ & $12.2 \pm 0.4$ & $<0.001$ \\
\hline Impact of symptoms (mean $\pm \mathrm{SE})$ & $6.5 \pm 0.3$ & $9.2 \pm 0.4$ & $<0.001$ \\
\hline
\end{tabular}

ERD, erosive reflux disease; NERD, nonerosive reflux disease; GERD, gastroesophageal reflux disease; GIS, GERD impact scale. Adjusted for gender, cigarette smoking, alcohol intake, income and body mass index in analysis of GIS. 


\section{Reflux Symptoms and GERD Impact Scale}

Patients with the reflux symptoms were significantly higher in the NERD group (100.0\%) than ERD group (85.7\%) $(P=$ $0.025)$. Both of esophageal symptoms $(P=0.002)$ and ex- tra-esophageal symptoms ( $P=0.002)$ were significantly higher in the NERD group than in the ERD group. We also analyzed symptoms and disturbances between ERD patients with symptoms and NERD patients. The positivity of symptoms was not different between 2 groups, except for the chest pain. The pa-

Table 3. Sleep Dysfunction, Anxiety, Depression and Quality of Life among Control, Erosive Reflux Disease and Nonerosive Reflux Disease Groups

\begin{tabular}{|c|c|c|c|c|c|c|}
\hline & $\begin{array}{c}\text { Control } \\
(\mathrm{n}=70)\end{array}$ & $\begin{array}{c}\text { ERD } \\
(n=70)\end{array}$ & $\begin{array}{l}\text { NERD } \\
(\mathrm{n}=77)\end{array}$ & $\begin{array}{c}\text { Control } \\
\text { vs. } \\
\text { ERD }\end{array}$ & $\begin{array}{l}\text { Control } \\
\text { vs. } \\
\text { NERD }\end{array}$ & $\begin{array}{c}\text { ERD } \\
\text { vs. } \\
\text { NERD }\end{array}$ \\
\hline PSQI score (mean $\pm \mathrm{SE})$ & $3.9 \pm 0.6$ & $5.2 \pm 0.6$ & $5.7 \pm 0.5$ & 0.005 & 0.030 & 0.774 \\
\hline ESS score $($ mean $\pm \mathrm{SE})$ & $3.5 \pm 0.9$ & $4.7 \pm 0.9$ & $5.0 \pm 0.7$ & 0.070 & 0.251 & 0.886 \\
\hline \multicolumn{7}{|l|}{ HADS score (mean \pm SE) } \\
\hline Total & $10.6 \pm 1.2$ & $13.5 \pm 1.3$ & $15.0 \pm 1.2$ & 0.074 & 0.007 & 0.903 \\
\hline Anxiety & $4.3 \pm 0.7$ & $6.2 \pm 0.7$ & $7.0 \pm 0.5$ & 0.004 & 0.002 & 0.972 \\
\hline Depression & $6.3 \pm 0.7$ & $7.2 \pm 0.6$ & $8.0 \pm 0.8$ & 0.439 & 0.062 & 0.745 \\
\hline \multicolumn{7}{|l|}{ WHOQOL-BREF score (mean \pm SE) } \\
\hline Total & $63.8 \pm 2.4$ & $57.8 \pm 2.4$ & $54.9 \pm 2.3$ & 0.014 & 0.002 & 0.630 \\
\hline Overall quality of life and general health & $6.9 \pm 0.3$ & $6.4 \pm 0.2$ & $5.6 \pm 0.2$ & 0.008 & 0.001 & 0.095 \\
\hline Physical domain & $14.0 \pm 0.5$ & $13.6 \pm 0.3$ & $12.0 \pm 0.6$ & 0.928 & 0.004 & 0.051 \\
\hline Psychological domain & $14.2 \pm 0.1$ & $13.1 \pm 0.5$ & $12.1 \pm 0.4$ & 0.015 & 0.002 & 0.334 \\
\hline Social domain & $14.2 \pm 0.5$ & $13.0 \pm 0.6$ & $12.5 \pm 0.6$ & 0.224 & 0.010 & 0.929 \\
\hline Environmental domain & $14.4 \pm 0.7$ & $12.5 \pm 0.6$ & $12.8 \pm 0.2$ & 0.018 & 0.072 & 0.560 \\
\hline
\end{tabular}

ERD, erosive reflux disease; NERD, nonerosive reflux disease; PSQI, Pittsburgh sleep quality index; ESS, Epworth sleepiness scale; HADS, Hospital anxiety and depression scale; WHOQOL-BREF, World Health Organization quality of life scale abbreviated version.

Adjusted for gender, cigarette smoking, alcohol intake, income and body mass index.

Table 4. Sleep Dysfunction, Anxiety, Depression and Quality of Life among Control, Erosive Reflux Disease with Symptoms and Nonerosive Reflux Disease Groups

\begin{tabular}{|c|c|c|c|c|c|c|}
\hline & $\begin{array}{l}\text { Control } \\
(\mathrm{n}=70)\end{array}$ & $\begin{array}{l}\text { ERD-S } \\
(n=60)\end{array}$ & $\begin{array}{l}\text { NERD } \\
(\mathrm{n}=77)\end{array}$ & $\begin{array}{l}\text { Control } \\
\text { vs. } \\
\text { ERD-S }\end{array}$ & $\begin{array}{c}\text { Control } \\
\text { vs. } \\
\text { NERD }\end{array}$ & $\begin{array}{c}\text { ERD-S } \\
\text { vs. } \\
\text { NERD }\end{array}$ \\
\hline PSQI score (mean $\pm \mathrm{SE})$ & $3.9 \pm 0.6$ & $5.2 \pm 0.7$ & $5.7 \pm 0.6$ & 0.035 & 0.030 & 0.735 \\
\hline ESS score $($ mean $\pm \mathrm{SE})$ & $3.5 \pm 0.9$ & $4.9 \pm 0.9$ & $5.0 \pm 0.7$ & 0.052 & 0.251 & 0.784 \\
\hline \multicolumn{7}{|l|}{ HADS score (mean $\pm \mathrm{SE})$} \\
\hline Total & $10.6 \pm 1.2$ & $13.7 \pm 1.3$ & $15.0 \pm 1.3$ & 0.059 & 0.007 & 0.976 \\
\hline Anxiety & $4.3 \pm 0.6$ & $6.3 \pm 0.7$ & $7.0 \pm 0.5$ & 0.002 & 0.002 & 0.982 \\
\hline Depression & $6.3 \pm 0.7$ & $7.3 \pm 0.6$ & $8.0 \pm 0.8$ & 0.427 & 0.062 & 0.746 \\
\hline \multicolumn{7}{|l|}{ WHOQOL-BREF score (mean $\pm \mathrm{SE}$ ) } \\
\hline Total & $63.8 \pm 2.4$ & $57.4 \pm 2.5$ & $54.9 \pm 2.6$ & 0.012 & 0.002 & 0.701 \\
\hline Overall quality of life and general health & $6.9 \pm 0.3$ & $6.4 \pm 0.2$ & $5.6 \pm 0.2$ & 0.020 & 0.001 & 0.121 \\
\hline Physical domain & $14.0 \pm 0.5$ & $13.5 \pm 0.3$ & $12.0 \pm 0.6$ & 0.965 & 0.004 & 0.060 \\
\hline Psychological domain & $14.2 \pm 0.6$ & $13.0 \pm 0.5$ & $12.1 \pm 0.4$ & 0.015 & 0.002 & 0.337 \\
\hline Social domain & $14.2 \pm 0.5$ & $12.9 \pm 0.6$ & $12.5 \pm 0.6$ & 0.241 & 0.010 & 0.960 \\
\hline Environmental domain & $14.4 \pm 0.7$ & $12.4 \pm 0.8$ & $12.8 \pm 0.6$ & 0.018 & 0.072 & 0.507 \\
\hline
\end{tabular}

ERD-S, erosive reflux disease with symptoms; NERD, nonerosive reflux disease; PSQI, Pittsburgh sleep quality index; ESS, Epworth sleepiness scale; HADS, Hospital anxiety and depression scale; WHOQOL-BREF, World Health Organization quality of life scale abbreviated version.

Adjusted for gender, cigarette smoking, alcohol intake, income and body mass index. 
tients with NERD more suffered with chest pain $(P=0.006)$.

In addition, GERD symptoms score and impact of symptoms score were also calculated in ERD patients with symptoms and NERD patients according to GIS questionnaire, when we adjusted for age, gender, cigarette smoking, alcohol intake, income and BMI. ERD with symptom group showed $9.8 \pm 0.4$ and $6.5 \pm 0.3$, and NERD group $12.2 \pm 0.4$ and $9.2 \pm 0.4$, respectively (Table 2). Although there was no difference in terms of positivity of GERD symptoms between 2 groups, GIS score was significantly higher in the NERD than the ERD with symptom group $(P<0.001$ and $P<0.001)$ (Table 2$)$.

\section{Sleep Dysfunction, Anxiety, Depression and Quality of Life}

When age, gender, cigarette smoking, alcohol intake, income and BMI were adjusted, the mean PSQI score was higher in the $\operatorname{ERD}(5.2 \pm 0.6)$ and NERD $(5.7 \pm 0.5)$ groups than in the control group $(3.9 \pm 0.6)(P=0.005$ and $P=0.030$, respectively). The mean ESS score was slightly higher in the NERD group, but it was not significantly different among the 3 groups. The mean HADS total score was higher in the NERD $(15.0 \pm 1.2)$ group than control $(10.6 \pm 1.2)$ group $(P=$ $0.007)$. The mean HADS score of anxiety subscale was also higher in the $\operatorname{ERD}(6.2 \pm 0.7)$ and $\operatorname{NERD}(7.0 \pm 0.5)$ groups than control group $(4.3 \pm 0.7)(P=0.004$ and $P=0.002$, respectively). In respect of QOL, WHOQOL-BREF of total, overall QOL and general health, and psychological domain scores were lower in the NERD $(P=0.002 ; P=0.001 ; P=$ 0.002 , respectively) and $\mathrm{ERD}(P=0.014 ; P=0.008 ; P=$ 0.015 , respectively) than control group. The score of the environmental domain was lower in ERD group than control group $(P$ $=0.018)$. In case of physical domain and social domain, the scores were lower in the NERD group than that of the control groups $(P=0.004$ and $P=0.010)$. When the ERD and NERD groups were compared, the tendency of higher PSQI, ESS and HADS scores and lower WHOQOL-BREF scores were noted in the NERD than ERD groups, but statistical difference was not observed (Table 3). The results were similar comparing between ERD with symptom and NERD groups (Table 4).

\section{Discussion}

There have been many studies regarding the effect of GERD on the QOL. However, there have been few studies, which com- pared QOL between ERD and NERD using the GIS questionnaire. In addition, the effect of GERD symptoms was analyzed comprehensively on the aspect of depression and anxiety by using the qualified questionnaires. It is also true that there have been scare data regarding sleep and GERD in Asia including Korea, where the prevalence of GERD is rather lower than in the Western countries.

In terms of basic characteristics, male was dominant in the ERD group, which is similar to the finding of the previous studies, which reported that ERD arose more frequently in male. ${ }^{18,32}$ However, female was not dominent in the NERD group, consistent with the findings of a Korean surveillance study. ${ }^{33}$ The mean BMI was significantly higher in ERD than control and NERD groups. This result supported previous studies. ${ }^{34}$ Interestingly, the BMI of female control group was slightly lower than the result of Korean survey in which the mean female BMI was around 23 with mean age of $45 .^{35}$ In addition, BMI was not associated with ERD in male subgroup, which could be originated from the high income state of control group. ${ }^{36}$ There was a previous report that obesity was more frequent in well-educated men with high income, while it was lesser in women with same condition. ${ }^{37}$

Our study showed that GERD symptoms were more frequent and severe in the NERD group, even when there was no organic lesion in upper GI endoscopy. Although there were no significant differences between the ERD with symptom and NERD group when we compared the presence or absence of symptoms, the severity of the symptoms and disturbance observed in GIS were worse in the patients with NERD. These results suggest that not only organic, but also other causes, such as visceral sensitivity, esophageal motility, and psychological factor could influence NERD, which has been proposed in other studies as well. ${ }^{38-40}$ Previously, we reported that patients with NERD visited emergency center more often and they spent more medical cost than patients with ERD. ${ }^{41}$ GIS is the scoring system not only for GERD symptom, but also for GERD symptom-induced disturbance in daily life, with consideration of frequency. GERD symptom and disturbance in daily life were different between the 2 groups in the present study. That is, disturbance in daily activities was more severe in the NERD group than the ERD group in analysis of GIS, which supports that there might be different etiology between ERD and NERD.

Sleep is important in the maintenance of homeostasis. It is influenced by complicated components, such as emotional factor, underlying condition, age, and gender. It has been reported re- 
garding the association of GERD with sleep dysfunction, ${ }^{42,43}$ emotional status, ${ }^{44}$ and QOL, ${ }^{45}$ usually in the Western countries. In Asia, there were few studies regarding sleep and GERD. Some studies reported that sleep was not disturbed by ERD itself, but reflux symptoms induced sleep dysfunction. ${ }^{46,47}$ However, there were controversies in comparing ERD and NERD. It was also reported that sleep dysfunction was noted in GERD patients, despite of no difference between ERD and NERD. ${ }^{48}$ This study is based on PSQI score, but small number of study population is one of the limitation of our study. Quality of sleep measured by PSQI was worse in the NERD (5.7 \pm 0.5$)$ group than control group $(3.9 \pm 0.6)$ in the present study. The significance disappeared when we compared ERD and NERD groups, suggesting GERD regardless of whether ERD (5.2 \pm 0.6) or NERD, affects quality of sleep. But worse tendency of quality of sleep was observed in the NERD than ERD group. In terms of day time sleepiness (measured by ESS) the prevalence was too rare to show any difference among the 3 groups. In Korea, shorter sleep duration was generally observed than Western countries. ${ }^{49,50}$ There was a possibility that shorter duration of sleep could influence these insignificant results.

Anxiety appeared to be associated with GERD in HADS. In the NERD group, the mean HADS total $(15.0 \pm 1.2)$, anxiety $(7.0 \pm 0.5)$ and depression $(8.0 \pm 0.8)$ subscales were higher than the categorization of cut off value itself of HADS, 10 and 7. These suggested that patients with NERD frequently feel anxiety and depressed mood. These results might be related with other results in that intensity of symptoms or impact on daily activities was more severe in the NERD than control group in the present study. Patients who are anxious might feel the same intensity of pain as the more severe one. The mean score of depression subscale also showed increasing tendency in the NERD group, but there was no statistical significance. It suggests that anxiety is more related with NERD than depression.

In terms of QOL, patients with GERD, both ERD and NERD, showed the significant deterioration than control group. Overall QOL and general health score and the psychological domain score (including self-esteem, positive and negative thinking, and learning) were lower in the GERD group than the control. However the physical domain (including discomfort, sleep, activity of daily living, and work capacity) was worse in the NERD than control. The satisfactions in socioeconomic state were significantly lower in the GERD group than control. However, the tendency of more severe deterioration of QOL in the patients with NERD than with ERD was also identified. It suggests that deterioration in the QOL is more distinct in the NERD group, and it is, especially, affected by a physical component. A previous report suggested that deterioration in the QOL was severe in patients with extra-esophageal symptoms ${ }^{51,52}$ and related with psychological factors, including both symptoms and mental components in patients with ERD and NERD subtype. ${ }^{44}$ As anxiety was significantly higher in GERD than control group, these results might support that anxiety could be important for the determination of QOL.

Sleep, emotion and QOL were affected by several factors, such as economic state, social habits and family stress. So we had adjusted for gender, smoking, alcohol and income, when we analyzed sleep dysfunction, emotional status and QOL. However, these results should be interpreted with caution because other factors which might affect those states could exist.

GERD was induced by transient relaxation of the lower esophageal sphincter, decrease of peristalsis of esophagus and swallowing to acid stimulation. ${ }^{53}$ And it has been reported that hypersensitivity and mis- or hyper-perception were existed in NERD. ${ }^{53}$ This was not limited to acidic stimuli only, but also included other stimuli such as pain. ${ }^{54}$ In the present study, anxiety which considered to be associated with sensitivity and deterioration of QOL was frequently observed in the NERD group. That is, NERD patients suffer more severe GERD symptoms originated from the combined effect of hypersensitivity of esophagus itself and the psychological problem. These conditions affect and exacerbate each other, resulting in vicious cycle in the patients with NERD. Taken together, our results support hypersensitivity and misperception as the mechanisms of NERD.

Our study has several limitations. First, NERD was not proved with ambulatory impedance $\mathrm{pH}$ monitoring in this study. So patients with functional dyspepsia could have been enrolled. ${ }^{55,56}$ Overlapping with irritable bowel syndrome was not checked also. This might be another confounder for the study results. Instead, we adopted the PPI response as diagnostic criteria of NERD. That is, we determined the PPI response by using standard dose with once daily regimen for 2 weeks, and the patients who improved more than $50 \%$ in symptoms with PPI were considered as NERD patients. ${ }^{57}$ A response to PPI does not confirm to a GERD diagnosis based on reflux testing. However, it was difficult to accomplish ambulatory impedance $\mathrm{pH}$ monitoring to every patient. And the observation that 40 to 90 percent of patients with symptoms suggestive of GERD have symptomatic response to PPI raises the question of which diag- 
nostic approach is more relevant in practice. ${ }^{58} \mathrm{~A}$ meta-analysis also supported that PPI therapy is equally effective in well-defined ERD and NERD. ${ }^{59}$ In addition, as the controls and the GERD patients were enrolled from 2 different sources, i.e., one from health check-up subjects and the other from outpatient clinic there is possibility that the observed differences were actually the results from 2 different populations, but not from the GERD disease per se. Younger age, lower BMI and higher income in the control group than GERD patients could have been originated from this. However, other differences in baseline characteristics were considered mainly from the gender difference which was identified as one of the characteristics of disease in other studies. We also adjusted these differences when we analyzed the sleep, emotion and QOL.

In conclusion, our study showed that NERD patients felt more severe GERD symptom, and their daily activities were more affected than those of ERD patients. Sleep dysfunction was higher in the patients with NERD than control group. Anxiety and deterioration in the QOL were also severe in GERD, especially in NERD, compared to the control group, suggesting that the patients with NERD were suffering more from the disease and they might be more affected by psychological factors.

\section{Acknowledgements}

Medical Research Collaborating Center (MRCC) of Seoul National University Bundang Hospital was consulted about the statistical analysis of the present manuscript.

\section{References}

1. Vakil N, van Zanten SV, Kahrilas P, Dent J, Jones R. The Montreal definition and classification of gastroesophageal reflux disease: a global evidence-based consensus. Am J Gastroenterol 2006;101: 1900-1920.

2. Dent J, El-Serag HB, Wallander MA, Johansson S. Epidemiology of gastro-oesophageal reflux disease: a systematic review. Gut 2005; 54:710-717.

3. Goh KL, Wong HT, Lim CH, Rosaida MS. Time trends in peptic ulcer, erosive reflux oesophagitis, gastric and oesophageal cancers in a multiracial Asian population. Aliment Pharmacol Ther 2009;29: 774-780.

4. Lien HC, Chang CS, Yeh HZ, et al. Increasing prevalence of erosive esophagitis among Taiwanese aged 40 years and above: a comparison between two time periods. J Clin Gastroenterol 2009;43:926-932.

5. Kim JI, Kim SG, Kim N, et al. Changing prevalence of upper gastrointestinal disease in 28893 Koreans from 1995 to 2005. Eur J
Gastroenterol Hepatol 2009;21:787-793.

6. Jansson C, Nordenstedt H, Wallander MA, et al. Severe gastro-oesophageal reflux symptoms in relation to anxiety, depression and coping in a population-based study. Aliment Pharmacol Ther 2007;26:683-691.

7. Johnston BT, Gunning J, Lewis SA. Health care seeking by heartburn sufferers is associated with psychosocial factors. Am J Gastroenterol 1996;91:2500-2504.

8. Hampel H, Abraham NS, El-Serag HB. Meta-analysis: obesity and the risk for gastroesophageal reflux disease and its complications. Ann Intern Med 2005;143:199-211.

9. Fass R. Effect of gastroesophageal reflux disease on sleep. J Gastroenterol Hepatol 2010;25(suppl 1):S41-S44.

10. Jung HK, Choung RS, Talley NJ. Gastroesophageal reflux disease and sleep disorders: evidence for a causal link and therapeutic implications. J Neurogastroenterol Motil 2010;16:22-29.

11. Prasad M, Rentz AM, Revicki DA. The impact of treatment for gastro-oesophageal reflux disease on health-related quality of life: a literature review. Pharmacoeconomics 2003;21:769-790.

12. McDougall NI, Johnston BT, Collins JS, McFarland RJ, Love AH. Disease progression in gastro-oesophageal reflux disease as determined by repeat oesophageal $\mathrm{pH}$ monitoring and endoscopy 3 to 4.5 years after diagnosis. Eur J Gastroenterol Hepatol 1997;9:11611167.

13. Barlow WJ, Orlando RC. The pathogenesis of heartburn in nonerosive reflux disease: a unifying hypothesis. Gastroenterology 2005; 128:771-778.

14. Fullard M, Kang JY, Neild P, Poullis A, Maxwell JD. Systematic review: does gastro-oesophageal reflux disease progress? Aliment Pharmacol Ther 2006;24:33-45.

15. Pace F, Pallotta S, Vakil N. Gastroesophageal reflux disease is a progressive disease. Dig Liver Dis 2007;39:409-414.

16. Bresadola V, Adani GL, Londero F, et al. Non-erosive and uncomplicated erosive reflux diseases: Difference in physiopathological and symptom pattern. World J Gastrointest Pathophysiol 2011;2: 42-48.

17. Martinez SD, Malagon IB, Garewal HS, Cui H, Fass R. Non-erosive reflux disease (NERD) - acid reflux and symptom patterns. Aliment Pharmacol Ther 2003;17:537-545.

18. Lee ES, Kim N, Lee SH, et al. Comparison of risk factors and clinical responses to proton pump inhibitors in patients with erosive oesophagitis and non-erosive reflux disease. Aliment Pharmacol Ther 2009;30:154-164.

19. Fass R. Erosive esophagitis and nonerosive reflux disease (NERD): comparison of epidemiologic, physiologic, and therapeutic characteristics. J Clin Gastroenterol 2007;41:131-137.

20. Armstrong D, Bennett JR, Blum AL, et al. The endoscopic assessment of esophagitis: a progress report on observer agreement. Gastroenterology 1996;111:85-92.

21. Jones R, Coyne K, Wiklund I. The gastro-oesophageal reflux disease impact scale: a patient management tool for primary care. Aliment Pharmacol Ther 2007;25:1451-1459.

22. Jo SY, Kim N, Lim JH, et al. Comparison of gastroesophageal reflux disease symptoms and proton pump inhibitor response using gastroesophageal reflux disease impact scale questionnaire. J Neurogastroenterol Motil 2013;19:61-69. 
23. Buysse DJ, Reynolds CF 3rd, Monk TH, Berman SR, Kupfer DJ. The Pittsburgh Sleep Quality Index: a new instrument for psychiatric practice and research. Psychiatry Res 1989;28:193-213.

24. Johns MW. A new method for measuring daytime sleepiness: the Epworth sleepiness scale. Sleep 1991;14:540-545.

25. Bjelland I, Dahl AA, Haug TT, Neckelmann D. The validity of the Hospital Anxiety and Depression Scale. An updated literature review. J Psychosom Res 2002;52:69-77.

26. The WHOQOL Group. Development of the World Health Organization WHOQOL-BREF quality of life assessment. Psychol Med 1998;28:551-558.

27. Skevington SM, Lotfy M, O'Connell KA. The World Health Organization's WHOQOL-BREF quality of life assessment: psychometric properties and results of the international field trial. A report from the WHOQOL group. Qual Life Res 2004;13:299-310.

28. Sohn SI, Kim do H, Lee MY, Cho YW. The reliability and validity of the Korean version of the Pittsburgh Sleep Quality Index. Sleep Breath 2012;16:803-812.

29. Cho YW, Lee JH, Son HK, Lee SH, Shin C, Johns MW. The reliability and validity of the Korean version of the Epworth sleepiness scale. Sleep Breath 2011;15:377-384.

30. Oh S, Min K, Park D. A study on the standardization of the hospital anxiety and depression scale for Koreans: a comparison of normal, depressed and anxious group. J Korean Neuropsychiatr Assoc 1999;38: 289-296.

31. Min SK, Kim KI, Lee CI, Jung YC, Suh SY, Kim DK. Development of the Korean versions of WHO Quality of Life scale and WHOQOL-BREF. Qual Life Res 2002;11:593-600.

32. Carlsson R, Dent J, Watts R, et al. Gastro-oesophageal reflux disease in primary care: an international study of different treatment strategies with omeprazole. International GORD Study Group. Eur J Gastroenterol Hepatol 1998;10:119-124.

33. Kim N, Lee SW, Cho SI, et al. The prevalence of and risk factors for erosive oesophagitis and non-erosive reflux disease: a nationwide multicentre prospective study in Korea. Aliment Pharmacol Ther 2008;27:173-185.

34. El-Serag HB, Graham DY, Satia JA, Rabeneck L. Obesity is an independent risk factor for GERD symptoms and erosive esophagitis. Am J Gastroenterol 2005;100:1243-1250.

35. Kim Y, Suh YK, Choi H. BMI and metabolic disorders in South Korean adults: 1998 Korea National Health and Nutrition Survey. Obes Res 2004;12:445-453.

36. Kavanagh A, Bentley RJ, Turrell G, Shaw J, Dunstan D, Subramanian SV. Socioeconomic position, gender, health behaviours and biomarkers of cardiovascular disease and diabetes. Soc Sci Med 2010; 71:1150-1160.

37. Park HS, Park CY, Oh SW, Yoo HJ. Prevalence of obesity and metabolic syndrome in Korean adults. Obes Rev 2008;9:104-107.

38. Shi G, Bruley des Varannes S, Scarpignato C, Le Rhun M, Galmiche JP. Reflux related symptoms in patients with normal oesophageal exposure to acid. Gut 1995;37:457-464.

39. Fass R, Naliboff B, Higa L, et al. Differential effect of long-term esophageal acid exposure on mechanosensitivity and chemosensitivity in humans. Gastroenterology 1998;115:1363-1373.

40. Bradley LA, Richter JE, Pulliam TJ, et al. The relationship between stress and symptoms of gastroesophageal reflux: the influence of psy- chological factors. Am J Gastroenterol 1993;88:11-19.

41. Seo PJ, Kim N, Oh JC, et al. Comparison of direct medical care costs between erosive reflux disease and non-erosive reflux disease in Korean tertiary medical center. J Neurogastroenterol Motil 2010;16: 291-298.

42. Wallander MA, Johansson S, Ruigomez A, Garcia Rodriguez LA, Jones R. Dyspepsia in general practice: incidence, risk factors, comorbidity and mortality. Fam Pract 2007;24:403-411.

43. Mody R, Bolge SC, Kannan H, Fass R. Effects of gastroesophageal reflux disease on sleep and outcomes. Clin Gastroenterol Hepatol 2009;7:953-959.

44. Oh JH, Kim TS, Choi MG, et al. Relationship between psychological factors and quality of life in subtypes of gastroesophageal reflux disease. Gut Liver 2009;3:259-265.

45. Kamolz T, Pointner R, Velanovich V. The impact of gastroesophageal reflux disease on quality of life. Surg Endosc 2003;17:11931199.

46. Kusano M, Kouzu T, Kawano T, Ohara S. Nationwide epidemiological study on gastroesophageal reflux disease and sleep disorders in the Japanese population. J Gastroenterol 2008;43:833-841.

47. Chen MJ, Wu MS, Lin JT, et al. Gastroesophageal reflux disease and sleep quality in a Chinese population. J Formos Med Assoc 2009;108:53-60.

48. Yi $\mathrm{CH}, \mathrm{Hu} \mathrm{CT}$, Chen CL. Sleep dysfunction in patients with GERD: erosive versus nonerosive reflux disease. Am J Med Sci 2007;334:168-170.

49. Park S, Cho MJ, Chang SM, et al. Relationships of sleep duration with sociodemographic and health-related factors, psychiatric disorders and sleep disturbances in a community sample of Korean adults. J Sleep Res 2010;19:567-577.

50. Luckhaupt SE, Tak S, Calvert GM. The prevalence of short sleep duration by industry and occupation in the National Health Interview Survey. Sleep 2010;33:149-159.

51. Dean BB, Aguilar D, Johnson LF, et al. Night-time and daytime atypical manifestations of gastro-oesophageal reflux disease: frequency, severity and impact on health-related quality of life. Aliment Pharmacol Ther 2008;27:327-337.

52. Dubois RW, Aguilar D, Fass R, et al. Consequences of frequent nocturnal gastro-oesophageal reflux disease among employed adults: symptom severity, quality of life and work productivity. Aliment Pharmacol Ther 2007;25:487-500.

53. Harding SM. Sleep related gastroesophageal reflux. The tip of the iceberg is showing! J Clin Sleep Med 2007;3:514-515.

54. Reddy H, Staahl C, Arendt-Nielsen L, Gregersen H, Drewes AM, Funch-Jensen P. Sensory and biomechanical properties of the esophagus in non-erosive reflux disease. Scand J Gastroenterol 2007;42: 432-440.

55. Cremonini F, Wise J, Moayyedi P, Talley NJ. Diagnostic and therapeutic use of proton pump inhibitors in non-cardiac chest pain: a metaanalysis. Am J Gastroenterol 2005;100:1226-1232.

56. Wang WH, Huang JQ, Zheng GF, et al. Is proton pump inhibitor testing an effective approach to diagnose gastroesophageal reflux disease in patients with noncardiac chest pain?: a meta-analysis. Arch Intern Med 2005;165:1222-1228.

57. Lee SH, Jang BI, Jeon SW, et al. A multicenter, randomized, comparative study to determined the appropriate dose of lansoprazole for 
use in the diagnostic test for gastroesophageal reflux disease. Gut Liver 2011;5:302-307.

58. Ke MY. How to differentiate non-erosive reflux disease from functional heartburn. J Dig Dis 2012;13:605-608.
59. Weijenborg PW, Cremonini F, Smout AJ, Bredenoord AJ. PPI therapy is equally effective in well-defined non-erosive reflux disease and in reflux esophagitis: a meta-analysis. Neurogastroenterol Motil 2012;24:747-757, e350. 